\title{
Evaluation of the Droplets and Aerosols, Posing Potential Risks of COVID-19 Disease Infection Transmission in Dentistry: A Systematic Review and Meta-Analysis of Observational Studies
}

\author{
Ali Amiri1@, Fan $Q^{1}{ }^{1}$, Maria Beatriz Carrazzone Cal Alonso²@, Nadia Sotelo Núñez ${ }^{3}$, Olha \\ $\operatorname{Kozyk}^{4} \cdot(\mathbb{0}$
}

\begin{abstract}
'Department of Orthodontics, College of Stomatology, The First Affiliated Stomatological Hospital, Xi'an Jiaotong University, Xi'an 710004, PR China.

2Departament of Dentomaxillofacial Radiology, School of Dentistry, Union of the Great Lakes Colleges, São José do Rio Preto, SP, Brazil.

${ }^{3}$ Department of Orthodontics, School of Dentistry, Universidad Latinoamericana, Mexico City, Mexico.

${ }^{4}$ Department of Orthodontics, School of Dentistry, National Pirogov Memorial Medical University, Vinnitsya, Ukraine.
\end{abstract}

Correspondence: Ali Amiri, Department of Orthodontics, College of Stomatology, The First Affiliated Stomatological Hospital, Xi'an Jiaotong University, Xi’an 710004, PR China. E-mail: draliamiri2020@gmail.com

Academic Editor: Alessandro Leite Cavalcanti

Received: 20 December 2020 / Review: 26 March 2021 / Accepted: 29 April 2021

\begin{abstract}
How to cite: Amiri A, Qi F, Alonso MBCC, Núñez NS, Kozyk O. Evaluation of the droplets and aerosols, posing potential risks of covid-19 disease infection transmission in dentistry: a systematic review and meta-analysis of observational studies. Pesqui Bras Odontopediatria Clín Integr. 2021; 21:e0262. https://doi.org/10.1590/pboci.2021.126
\end{abstract}

\begin{abstract}
Objective: To evaluate the droplets and aerosols, posing potential risks of infection transmission of COVID-19 disease in dentistry. Material and Methods: PubMed, Embase, ISI, Scopus, Medicine have been used to search for articles between September 2019 to December 2020. Data extracted from the studies were included, study, study design, sample size, Sample collection time, Hallway Air Samples (copies/L of air), Personal Air Samples (copies/L of air). Effect size with 95\% confidence interval (CI), fixed effect model, Inverse-variance methods were calculated. The Meta-analysis was evaluated with Stata/MP v.16 statistical software (The fastest version of Stata). Results: According to the purpose of the study, 64 articles were found; studies that did not meet the inclusion criteria were excluded from the study; the full text of 11 studies was reviewed. Finally, two studies were selected. The effect size of airborne COVID-19 concentrations of the hallway and personal air samples was $64 \%$ copies/L of air $(\mathrm{ES}, 0.6495 \% \mathrm{CI}=-1.45-$ 2.73 ) and $100 \%$ copies/L air (ES, $1.0095 \% \mathrm{CI}=-1.77-3.76)$, respectively. Conclusion: Evidence of aerosol transmission of COVID-19 in observational studies of patients with COVID-19 was $64 \%$ copies/L of air and $100 \%$ copies/L of air in the hallway and personal air samples, respectively.
\end{abstract}

Keywords: Disease Transmission, Infectious; Aerosols; COVID-19; SARS-CoV-2. 


\section{Introduction}

In the current context of the world, since the advent of COVID-19 in Wuhan, China, in December 2019 [1], the disease has become a primary global health concern. On January 30, 2020, the WHO identified the outbreak of COVID-19 as the sixth health emergency after H1N1 (2009), polio (2014), Ebola in West Africa (2014), Zika Virus (2016), and Ebola (2019) [2]. Therefore, all health care workers, governments, and the general public must work together globally to prevent the spread of the virus [3]. According to the WHO, the global mortality rate over time was estimated at 5.7\%, using a 14-day estimate [4]. Researchers first reported that the disease's cause was local seafood markets that sold live animals; subsequent research showed that pathogens are transmitted from animals to humans, and then research reported that the pathogen it is transmitted from human to human [5]. In the sixth edition of the COVID-19 treatment regimen (Trial Implementation) [6], it was reported that the possible routes of transmission of COVID-19 are direct contact and transmission through respiratory particles. In addition, aerosols may be transferred in a closed environment, and more people are at risk for aerosol transmission [7].

On the other hand, in dentistry, aerosols can pose potential risks to the dentist and reciprocally to the patient due to their occupational nature. To date, there have been no reports of COVID-19 spreading in the dental environment. However, it should be noted that the disease is spreading rapidly and transmission; dentists, dental assistants, and all staff in the oral care department should be vigilant and create a healthy and disinfectant environment for themselves and patients. As a result, it is necessary to know how the disease is transmitted, understand the aerosol transmission, the consequences in dentistry, appropriate and standard measures, and precautionary measures. Therefore, according to the subject's importance, the present study aimed to evaluate the droplets and aerosols, posing potential risks of infection transmission of COVID-19 disease in dentistry.

\section{Material and Methods}

Search Method

PubMed, Embase, ISI, Scopus, Medicine were used between September 2019 to December 2020 to search the articles. EndNote X9 was therefore used to manage electronic resources. PubMed Searching was performed using mesh terms:

("COVID-19" [Mesh AND "SARS-CoV-2" $\sqsubset$ Mesh AND "COVID-19 Testing" $[$ Mesh) AND "Aerosols" [Mesh) AND ("Aerosol Propellants" $[$ Mesh OR "Aerosol Propellants" ¿Pharmacological Action)) AND "Saliva" $[$ Mesh) OR "Lipid Droplets" $[$ Mesh) AND "Disease Transmission, Infectious" $[$ Mesh) AND ("transmission" [Subheading OR "Microscopy, Electron, Transmission" [Mesh)) AND ("Dentistry" [Mesh OR "Evidence-Based Dentistry"[Mesh)) OR "Dental Health Services" $[$ Mesh) OR "Infection Control, Dental"[Mesh].

Inclusion criteria included observational studies. Randomized controlled trial studies, controlled clinical trials, prospective and retrospective cohort studies, case-control studies, in vitro studies Reviews, case series, and case reports were excluded from the present article. This systematic review has been conducted based on the key consideration of the PRISMA Statement-Preferred Reporting Items for the Systematic Review and Meta-analysis [8] and PICO strategy (Table 1). 
Table1. PECO strategy.

\begin{tabular}{cl}
\hline PECO Strategy & \multicolumn{1}{c}{ Description } \\
\hline P & Population: Aerosol samples from patients with positive for COVID 19 \\
E & Exposure: Evaluate the aerosol samples \\
C & Comparison: Hallway and persona air samples \\
O & Outcome: Results of air samples \\
\hline
\end{tabular}

Data Extraction Methods

Data extracted from the studies were included, authors, study design, sample size, Sample collection time, Hallway Air Samples (copies/L of air), Personal Air Samples (copies/L of air). Quality was assessed according to previously published guidelines [9]. In the first part of this article, the meta-analysis results are reported as a systematic literature review. Effect size with $95 \%$ confidence interval (CI) and fixed-effect model and Inverse-variance methods were calculated. To deal with potential heterogeneity, random effects were used, and $\mathrm{I}^{2}$ showed heterogeneity. $\mathrm{I}^{2}$ values above $50 \%$ signified moderate-to-high heterogeneity. The meta-analysis was evaluated using the statistical software Stata/MP v.16 (The fastest version of Stata).

\section{Results}

According to the purpose of the study, in the initial search with keywords, 64 articles were found. In the first step of selecting studies, 60 studies were selected to review the abstracts. Then, studies that did not meet the inclusion criteria were excluded from the study. In the second step, the full text of 11 studies was reviewed. Finally, two studies were selected (Figure 1).

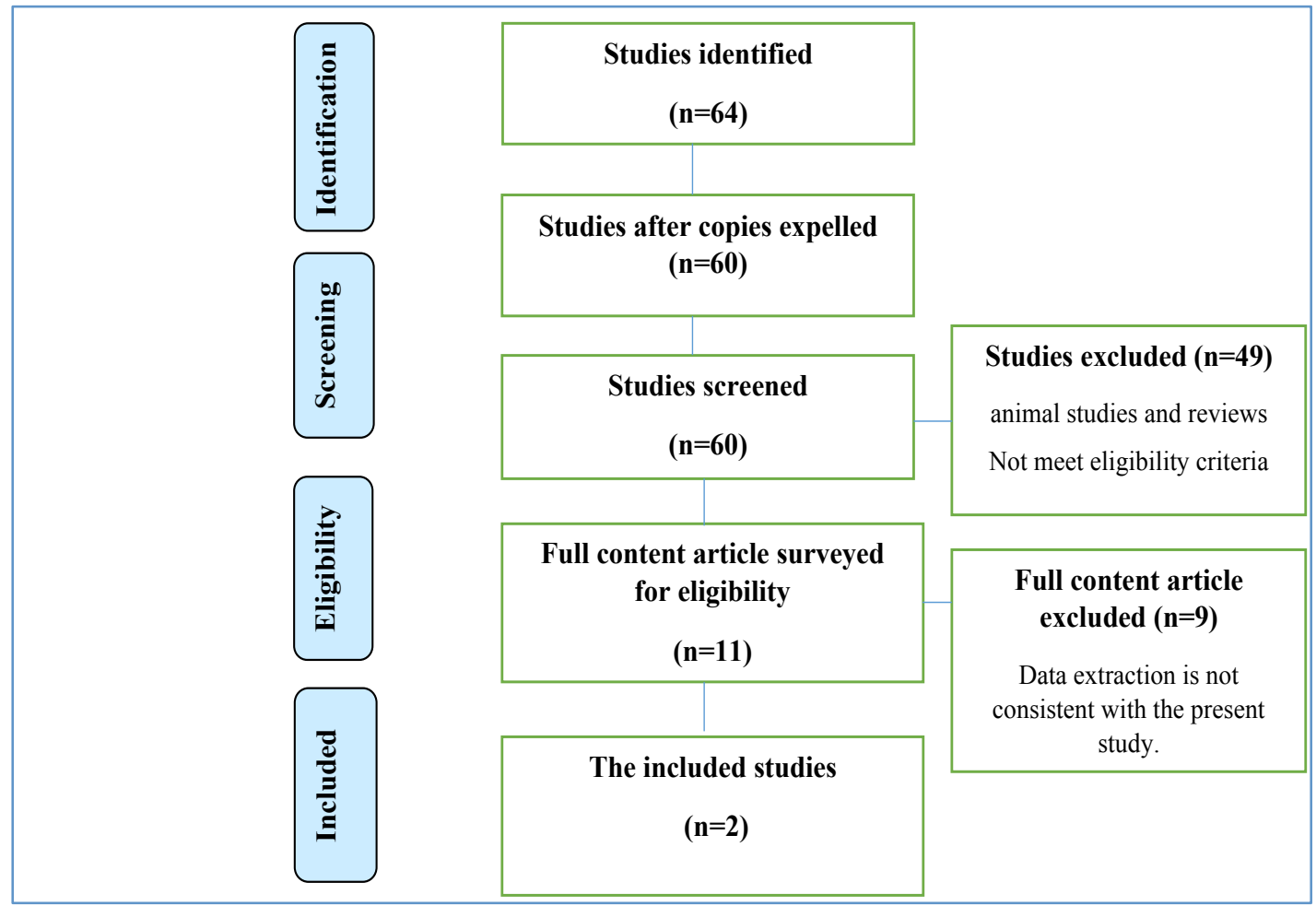

Figure 1. Study Attrition.

Two studies (observational studies) have been included in the present article. The number of aerosol samples total was 198 (Table 2). All studies included have a low risk of bias (Table 3). 
Table 2. Details of selected studies according to inclusion criteria.

\begin{tabular}{cccccc}
\hline \multicolumn{1}{c}{ Authors } & Study Design & $\begin{array}{c}\text { Aerosol } \\
\text { Samples }\end{array}$ & $\begin{array}{c}\text { Sample } \\
\text { Collection Time }\end{array}$ & $\begin{array}{c}\text { Hallway Air Samples Personal Air Samples } \\
\text { (copies/L of air) }\end{array}$ & $\begin{array}{c}\text { Popies/L of air) } \\
\text { (copion }\end{array}$ \\
\hline Santarpia et al., 2020 [10] & Observational & 163 & NR & $66.7 \%$ & $99.1 \%$ \\
Liu et al., 2020 [11] & Observational & 35 & $\begin{array}{c}\text { February 17 and } \\
\text { March 2, 2020 }\end{array}$ & 54.28 & 9 \\
\hline
\end{tabular}

Table 3. Risk of bias assessment.

\begin{tabular}{|c|c|c|c|c|c|c|c|}
\hline Authors & $\begin{array}{c}\text { Study } \\
\text { Participation }\end{array}$ & $\begin{array}{c}\text { Study } \\
\text { Attrition }\end{array}$ & $\begin{array}{c}\text { Prognostic } \\
\text { Factor } \\
\text { Measurement }\end{array}$ & $\begin{array}{c}\text { Outcome } \\
\text { Measurement }\end{array}$ & $\begin{array}{l}\text { Confounding } \\
\text { Measurement } \\
\text { and Account }\end{array}$ & $\begin{array}{c}\text { Analysis } \\
\text { Appropriate }\end{array}$ & $\begin{array}{c}\text { Risk } \\
\text { Assessment }\end{array}$ \\
\hline $\begin{array}{c}\text { Santarpia et al., } \\
2020[10]\end{array}$ & & 2 & & & & & Low \\
\hline $\begin{array}{c}\text { Liu et al., } 2020 \\
{[11]}\end{array}$ & & $?$ & $?$ & & & & Low \\
\hline
\end{tabular}

Evidence of Airborne Transmission of COVID-19

The effect size of airborne COVID-19 concentrations of hallway air samples was $64 \%$ copies/L of air (ES, 0.64 95\% CI= -1.45-2.73), heterogeneity found $\mathrm{I}^{2}=-0 \%$ (Figure 2 ). The effect size of airborne COVID-19 concentrations of personal air samples was $100 \%$ copies $/ \mathrm{L}$ of air $(\mathrm{ES}, 1.0095 \% \mathrm{CI}=-1.77-3.76)$ and heterogeneity found $\mathrm{I}^{2}=-0 \%$ (Figure 3 ).

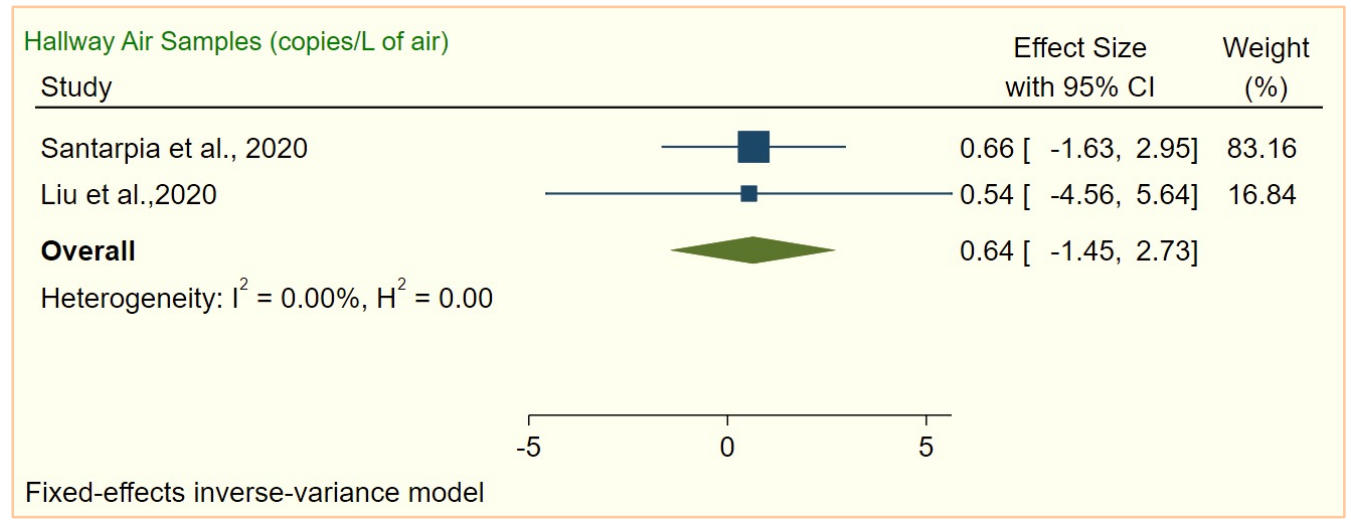

Figure 2. Effect size of airborne COVID-19 concentrations of hallway air samples.

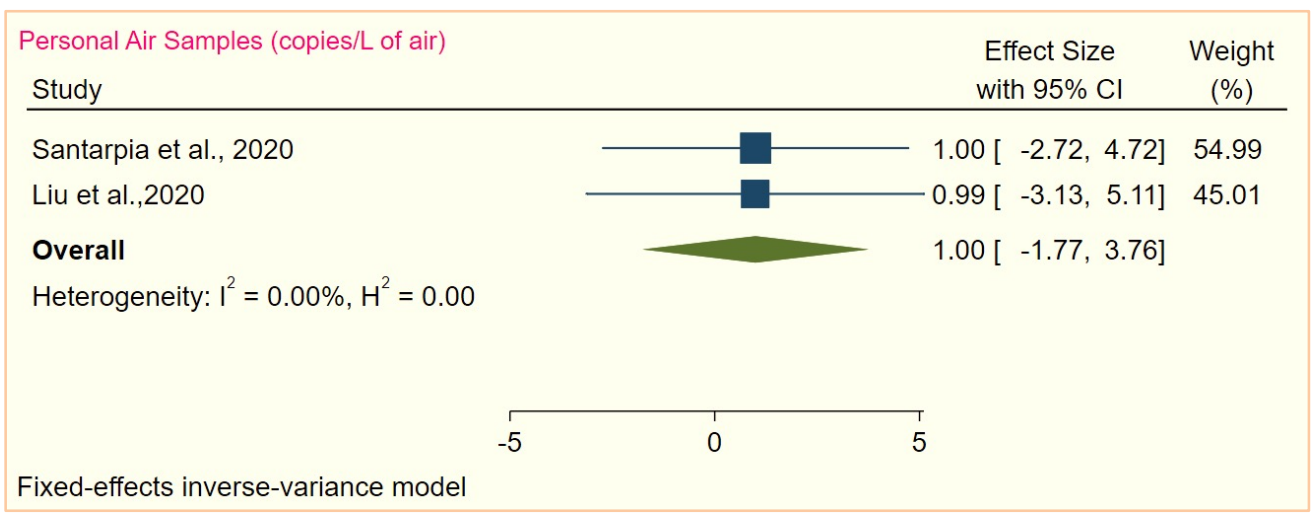

Figure 3. Effect size of airborne COVID-19 concentrations of personal air samples. 


\section{Discussion}

The present systematic review and Meta-analysis found insufficient evidence of aerosol transmission of COVID-19; the hallway and personal air samples' outcome was $64 \%$ copies/L of air and 100\% copies/L of air, Respectively. According to the WHO (2014), aerosol droplets are produced when coughing, laughing, talking, or sneezing. Aerosol droplets are droplets smaller than five $\mu \mathrm{m}$ diameter and larger droplets larger than five $\mu \mathrm{m}$ diameter. Small droplets settle faster than larger droplets and stay in the air longer, while large droplets fall to the ground quickly and can be transferred to another person in less time. Baghizadeh Fini [12], examine the routes of respiratory virus transmission among humans; the result showed respiratory viruses are transmitted via contact, droplets, or aerosols. Also, Otter et al. [13] evaluate the evidence that contaminated surfaces contribute to the transmission of hospital pathogens; the result showed contaminated surfaces contribute to transmission. According to reports, the COVID-19 can also be transmitted through contact with infected surfaces.

Farah et al. [14] evaluate the effect of cooling water temperature on pulp chamber temperature changes and showed that too much heat is generated when using a high-speed handpiece, which should use a water coolant. Water coolants can create aerosols, and when combined with saliva in the oral cavity, bioaerosols are formed. Bio-aerosols originate from various sources and can pose a hazard to healthcare workers and patients due to their potential pathogenic nature. Zemouri et al. [15], in a review, reported that 38 types of microorganisms found in the dental clinic air and both patients and health workers, all aerosols could be hazardous. Several studies show that the transmission of COVID-19 occurs mostly through oral droplets [1619]. As mentioned in the introduction, the disease's incubation period is 14 days, and early detection without testing is impossible. The virus can also be transmitted during the incubation period. Given the unique nature of dentistry and the use of devices that produce significant amounts of droplets and aerosols, the importance of aerosol transfer and its consequences in dentistry should be considered, and a potential guide to dentists' guidance reported. In addition to standard precautions, special precautions should be taken at the time of the outbreak. Yu et al. [20] investigate the resumption of endodontic practices. The result showed there is a concern among endodontic clinicians of contracting/spreading COVID-19. The fear is negatively associated with years of practice, and most clinicians believe they and their patients can be protected from COVID-19 by rubber dam isolation. The present study had some limitations, the sample size was small, and sample collection time was not reported in one study, and only two studies were found. However, it is not possible to determine whether the studies were erroneous or poorly reported.

Further studies are needed in this regard. A high sample size is recommended for future studies. Also, the lack of studies in this field means that the results of this study do not provide sufficient evidence. In addition to general precautions, the following measures are recommended:

1) Use of rubber dam in endodontic practice is important for several reasons. In COVID-19, the rubber dam creates an operational environment without infection and isolates the tooth from oral and salivary contamination, and reduces or eliminates the presence of salivary components in the aerosol.

2) Unnecessary hand contact with endodontic instruments, devices, and equipment should be minimized.

3) After the end of the dental treatment and the patient leaving and before the arrival of another patient, the whole room should be disinfected by dental healthcare personnel. This allows droplets to fall sufficiently from the air after a dental procedure.

4) Use N95 masks or facemask and full-face shield to prevent the transfer of aerosols.

5) Use eye protection during dental practice and should be discarded after use. 
6) Disposable gloves are required and should be discarded after each use. The use of gloves minimizes the risk of aerosol transmission from the patients to dental healthcare personnel and conversely.

7) Use rotary instruments for a root canal to reduce droplet production, splatter, and aerosols by dental drills and saliva.

8) Use rubber dam isolation to reduce the transmission of saliva to dental healthcare personnel hands.

9) To reduce the burden of pediatric visits, proper brushing techniques, fluoride toothpaste, flossing, and all methods of caring for cocaine should be taught to children and their parents wholly and correctly.

10) Hand instruments and ultrasonic scalers are used mostly to prevent periodontal disease and remove deposits on the tooth surface. On the other hand, an ultrasonic scaler is one of the largest producers of spatter droplets and aerosols used in dentistry. Therefore, it is recommended to use hand instruments in the covid-19 epidemic to reduce transmission risk through droplets and aerosols.

Finally, droplets containing COVID-19 can be dispersed on the surrounding surfaces and remain during the aerosol production process. Studies have shown that COVID-19 can remain on surfaces for up to 9 days. Therefore, the result on all surfaces should be cleaned with surface disinfectants within one minute after each patient visit.

\section{Conclusion}

Evidence of aerosol transmission of COVID-19 in observational studies of patients with COVID-19 was $64 \%$ copies/L of air and $100 \%$ copies/L of air in the hallway and personal air samples, respectively. Dentists are more at risk for COVID-19, so new challenges and responsibilities need to be defined for them. They need to know the risk of aerosol transmission and the consequences of not following the protocols to their detriment. In addition to standard precautions, special precautions should be taken to prevent transmission of the disease from asymptomatic carriers. All protocols can be used as a guide to control the prevalence of COVID-19 and used in the prevention of other respiratory diseases.

\section{Authors' Contributions}

\begin{tabular}{|c|c|c|}
\hline & (iD) https://orcid.org/0000-0001-94.16-808X & $\begin{array}{l}\text { Conceptualization, Methodology, Validation, Formal Analysis, Investigation, Data Curation, } \\
\text { Writing - Original Draft, Writing - Review and Editing and Supervision. }\end{array}$ \\
\hline FQ & https://orcid.org/0000-0002-9982-6755 & Methodology, Validation, Writing - Original Draft and Writing - Review and Editing. \\
\hline MBCA & (D) https://orcid.org/0000-0002-4989-7811 & Methodology, Formal Analysis, Writing - Original Draft and Writing - Review and Editing. \\
\hline NSN & (iD) https://orcid.org/0000-0003-1269-1235 & Methodology, Writing - Original Draft and Writing - Review and Editing. \\
\hline OK & (iD) https://orcid.org/0000-0001-5541-2203 & Methodology, Formal Analysis, Writing - Original Draft and Writing - Review and Editing. \\
\hline
\end{tabular}

\section{Financial Support}

None.

\section{Conflict of Interest}

The authors declare no conflicts of interest.

\section{Data Availability}

The data used to support the findings of this study can be made available upon request to the corresponding author.

\section{References}

[1] Casaroto AR, Jamali J, Amini F, Talebzade Toranji M, Kayasöken G. Evaluation epidemiology, symptoms, and routes of COVID-19 for dental care: a literature review. IJSRDMS 2020; 2(2):37-41. https://doi.org/10.30485/IJSRDMS.2020.231680.1056 
[2] Wei FF, Moradkhani A, Hemmati Hezaveh H, Miraboutalebi SA, Salehi L. Evaluating the treatment with favipiravir in patients infected by COVID-19: a systematic review and meta-analysis. IJSRDMS 2020; 2(3):87-91. https://doi.org/10.30485/IJSRDMS.2020.241494.1079

[3] Aponte Mendez M, Rivera Marval EK, Talebzade Toranji M, Amini F, Casaroto AR. Dental care for patients during the Covid-19 outbreak: a literature review. IJSRDMS 2020; 2(2):42-5. https://doi.org/10.30485/IJSRDMS.2020.232096.1058

[4] Gaye B, Fanidi A, Jouven X. Denominator matters in estimating COVID-19 mortality rates. Eur Heart J 2020; 41(37):3500. https://doi.org/10.1093/eurheartj/ehaa282

[5] Pfefferbaum B, North CS. Mental health and the Covid-19 pandemic. N Engl J Med 2020; 383:510-2. https://doi.org/10.1056/NEJMp2008017

[6] Chen J. Pathogenicity and transmissibility of 2019-nCoV - a quick overview and comparison with other emerging viruses. Microbes Infect 2020; 22(2):69-71.https://doi.org/10.1016/j.micinf.2020.01.004

[7] Wang J, Du G. COVID-19 may transmit through aerosol. Ir J Med Sci 2020; 189(4):1143-4. https://doi.org/10.1007/s11845-020-02218-2

[8] Moher D, Liberati A, Tetzlaff J, Altman DG, Altman D, Antes G, et al. Preferred reporting items for systematic reviews and meta-analyses: The PRISMA statement (Chinese edition). Chin J Integr Med 2009; 7(9):889-96. https://doi.org/10.3736/jcim20090918

[9] Hayden JA, Côté P, Bombardier C. Evaluation of the quality of prognosis studies in systematic reviews. Ann Intern Med 2006; 144(6):427-37. https://doi.org/10.7326/0003-4819-144-6-200603210-00010

[10] Santarpia JL, Rivera DN, Herrera V, Morwitzer MJ, Creager H, Santarpia GW, et al. Transmission potential of SARS-CoV-2 in viral shedding observed at the University of Nebraska Medical Center. MedRxIV 2020; 2020. https://doi.org/10.1101/2020.03.23.20039446

[11] Liu Y, Ning Z, Chen Y, Guo M, Liu Y, Gali NK, et al. Aerodynamic characteristics and RNA concentration of SARSCoV-2 aerosol in Wuhan hospitals during COVID-19 outbreak. BioRxiv 2020; 2020. https://doi.org/10.1101/2020.03.08.982637

[12] Baghizadeh Fini M. Transmission routes of SARS-CoV-2 in dentistry: a literature review. IJSRDMS 2020; 2(4):1357. https://doi.org/10.30485/ijsrdms.2020.252402.1088

[13] Otter JA, Yezli S, Salkeld JA, French GL. Evidence that contaminated surfaces contribute to the transmission of hospital pathogens and an overview of strategies to address contaminated surfaces in hospital settings. Am J Infect Control 2013; 41(5):S6-11. https://doi.org/10.1016/j.ajic.2012.12.004

[14] Farah RI. Effect of cooling water temperature on the temperature changes in pulp chamber and at handpiece head during high-speed tooth preparation. RDE 2019; 44(1):e3. https://doi.org/10.5395/rde.2019.44.e3

[15] Zemouri C, de Soet H, Crielaard W, Laheij A. A scoping review on bio-aerosols in healthcare and the dental environment. PloS one 2017; 12(5):e0178007. https://doi.org/10.1371/journal.pone.0178007

[16] Bahl P, Doolan C, de Silva C, Chughtai AA, Bourouiba L, MacIntyre CR. Airborne or droplet precautions for health workers treating COVID-19?. J Infect Dis 2020; 2020. https://doi.org/10.1093/infdis/jiaa189

[17] Morawska L, Tang JW, Bahnfleth W, Bluyssen PM, Boerstra A, Buonanno G, et al. How can airborne transmission of COVID-19 indoors be minimised?. Environ Int 2020; 142:105832. https://doi.org/10.1016/j.envint.2020.105832

[18] Gu J, Han B, Wang J. COVID-19: gastrointestinal manifestations and potential fecal-oral transmission. Gastroenterology 2020; 158(6):1518-9. https://doi.org/10.1053/j.gastro.2020.02.054

[19] Baghizadeh Fini M, Seraj B, Ghadimi S. COVID-19 in pediatric patients: a literature review. IJSRDMS 2020; 2(4):126-30. https://doi.org/10.30485/ijsrdms.2020.246164.1083

[20] Yu J, Hua F, Shen Y, Haapasalo M, Qin D, Zhao D, et al. Resumption of endodontic practices in COVID-19 hardesthit area of China: a Web-based survey. J Endod 2020; 46(11):1577-83. https://doi.org/10.1016/j.joen.2020.08.001 